\title{
Successful pregnancy in a patient with a homograft aortic valve
}

\author{
W. A. Littler \\ From Liverpool Regional Cardiac Centre, Sefton General Hospital, Liverpool 15
}

$A$ case is described of a 27-year-old woman whose aortic valve was replaced by a homograft. Eighteen months after the operation she gave birth to a normal healthy girl.

Experience in the management of pregnancy after successful prosthetic or homograft valve replacement is not great, and the potential hazards are numerous. This report concerns the management and progress of such a case, after successful homograft replacement of the aortic valve, performed because of severe aortic regurgitation.

\section{Case report}

This 27-year-old woman gave a past history of rheumatic fever at the age of 13 and again at 16. Aortic regurgitation was diagnosed when she was 19, but at that time she was symptomless, and no treatment was advised. At the age of 23 she began to complain of increasing effort dyspnoea, and of spontaneous nocturnal dyspnoea, and was started on treatment with lanatoside $\mathrm{C}$ and frusemide. The symptoms did not improve, but she never had true effort pain or syncope, and there was never any evidence of fluid retention.

She was referred to the Liverpool Regional Cardiac Centre for further assessment. Examination revealed evidence of a considerable degree of aortic regurgitation, viz. a collapsing pulse with a brachial blood pressure of $170 / 0 \mathrm{~mm} . \mathrm{Hg}$; a very loud prolonged parasternal diastolic murmur, and a short ejection systolic murmur at the base, radiating into the neck. The thrusting apex beat was preceded by a palpable ' $a$ ' wave, and a short mid-diastolic murmur was present at the apex. The first heart sound was normal, and was preceded by a $4^{\text {th }}$ sound, no 3 rd sound could be heard, and there was no ejection sound. The jugular pulse appeared normal, and the blood Wassermann reaction negative. The electrocardiogram showed a moderately severe degree of left ventricular hypertrophy; the phonocardiogram is shown in Fig. I. The PR interval is at the maximum limit of normal, but the prolonged aortic diastolic murmur is well shown, as is the bisferiens carotid pulse.
The cardiac outline on the chest radiograph (Fig. 2) showed selective left ventricular enlargement only. There was no evidence of left atrial enlargement, and no dilatation of the aorta. No calcification was seen in the area of the aortic valve, and there was no radiological evidence of pulmonary venous hypertension.

Right heart catheterization showed a mean pulmonary artery wedge pressure of $12 \mathrm{~mm}$. $\mathrm{Hg}$, the other right heart pressures being normal. Transseptal catheterization showed a direct mean left atrial pressure of $5 \mathrm{~mm}$. $\mathrm{Hg}$, with no diastolic gradient across the mitral valve, but the left ventricular end-diastolic pressure rose from 8 to $13 \mathrm{~mm}$. Hg after aortic angiography. Retrograde femoral artery catheterization showed no gradient in systole across the aortic valve, the left ventricular pressure being $155 / 8 \mathrm{~mm}$. $\mathrm{Hg}$, the aortic

\section{FIG. I Pre-operative phonocardiogram.}

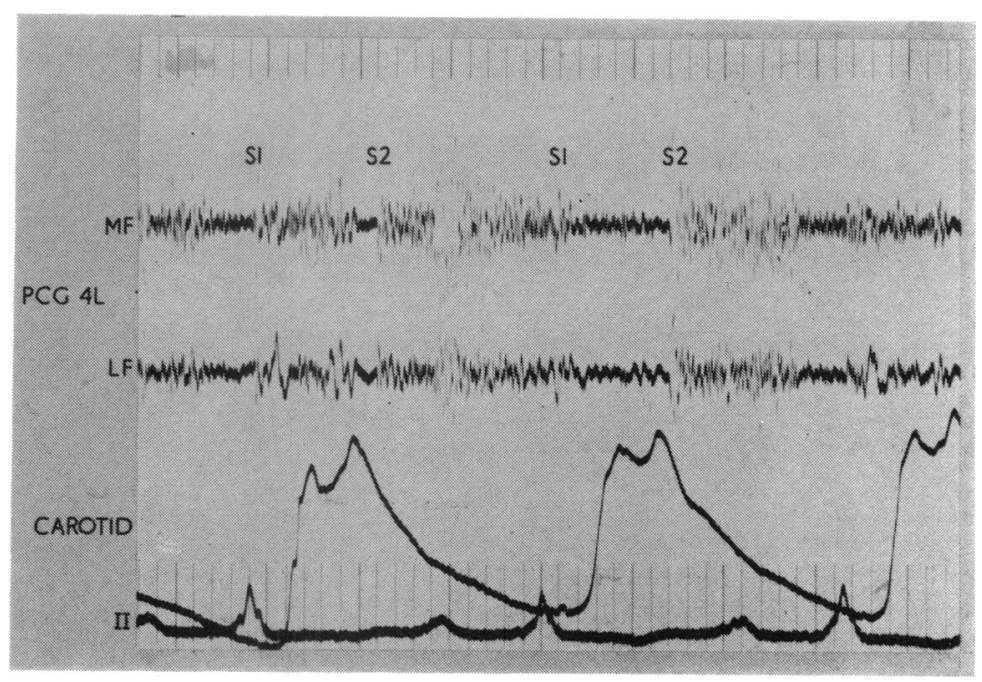


pressure $155 / 40 \mathrm{~mm}$. Hg. Aortic angiography showed a gross degree of aortic regurgitation through a wide central jet.

It was decided that aortic valve replacement was indicated, and at operation 6 months later, the commissures of the aortic valve were found to be widely separated, with shortening and thickening of the left coronary cusp. The valve was excised and replaced by a $26 \mathrm{~mm}$. saline preserved homograft. On recovery from the operation, it was noted she had a left bundlebranch block, and this electrocardiographic pattern has persisted. Otherwise her progress was uneventful, and she was discharged from hospital six weeks after operation. She still had a soft aortic diastolic murmur, with a very soft ejection systolic murmur, but no peripheral signs of aortic regurgitation. The brachial blood pressure was $130 / 90 \mathrm{~mm}$. $\mathrm{Hg}$, and radiography showed considerable diminution of the cardiac outline.

Six months after operation, she married, and twelve months later became pregnant. She had been advised of the associated risks, but was anxious to have a child. Seen in the twelfth week of pregnancy, she was symptomless, and there was no change in her cardiac signs or the electrocardiogram. A transient rise in blood pressure to $155 / 105 \mathrm{~mm}$. $\mathrm{Hg}$ settled with bedrest and sedation and she was delivered of a normal healthy girl, weighing $3062 \mathrm{~g}$. on 24 March 1969. Oral penicillin $250 \mathrm{mg}$. 6-hourly and nystatin 500,000 units 8-hourly were given at the onset of parturition, and continued for 4 weeks. At no time did she need digitalis or diuretics, and when seen 6 weeks after delivery she was well, with no change in the physical signs in the cardiovascular system, and with an unchanged electrocardiogram and radiograph (Fig. 3).

\section{Discussion}

Experience in the management of pregnant women with prosthetic and homograft heart valves is still very limited. Published reports have dealt with the behaviour of prosthetic valves during pregnancy, and the outcome has been varied. Ueland, Tatum, and Metcalfe (I966) reported 2 patients with StarrEdwards aortic valves who were delivered of healthy infants after uncomplicated pregnancies. This successful outcome was also the experience of Turner and Kitchin (1968) in 2 patients with Starr-Edwards prostheses; in one case, of the mitral valve, and, in the other, of the aortic valve. Ueland et al. did not use anticoagulants in their 2 cases, while Turner and Kitchin treated both their patients with anticoagulants throughout pregnancy, stopping the phenindione at the onset of labour, and restarting it immediately
FIG. 2 Pre-operative chest radiograph showing left ventricular enlargement.
FIG. 3 Chest radiograph 6 weeks after a normal delivery showing left ventricular enlargement and some dilatation of the aortic root.
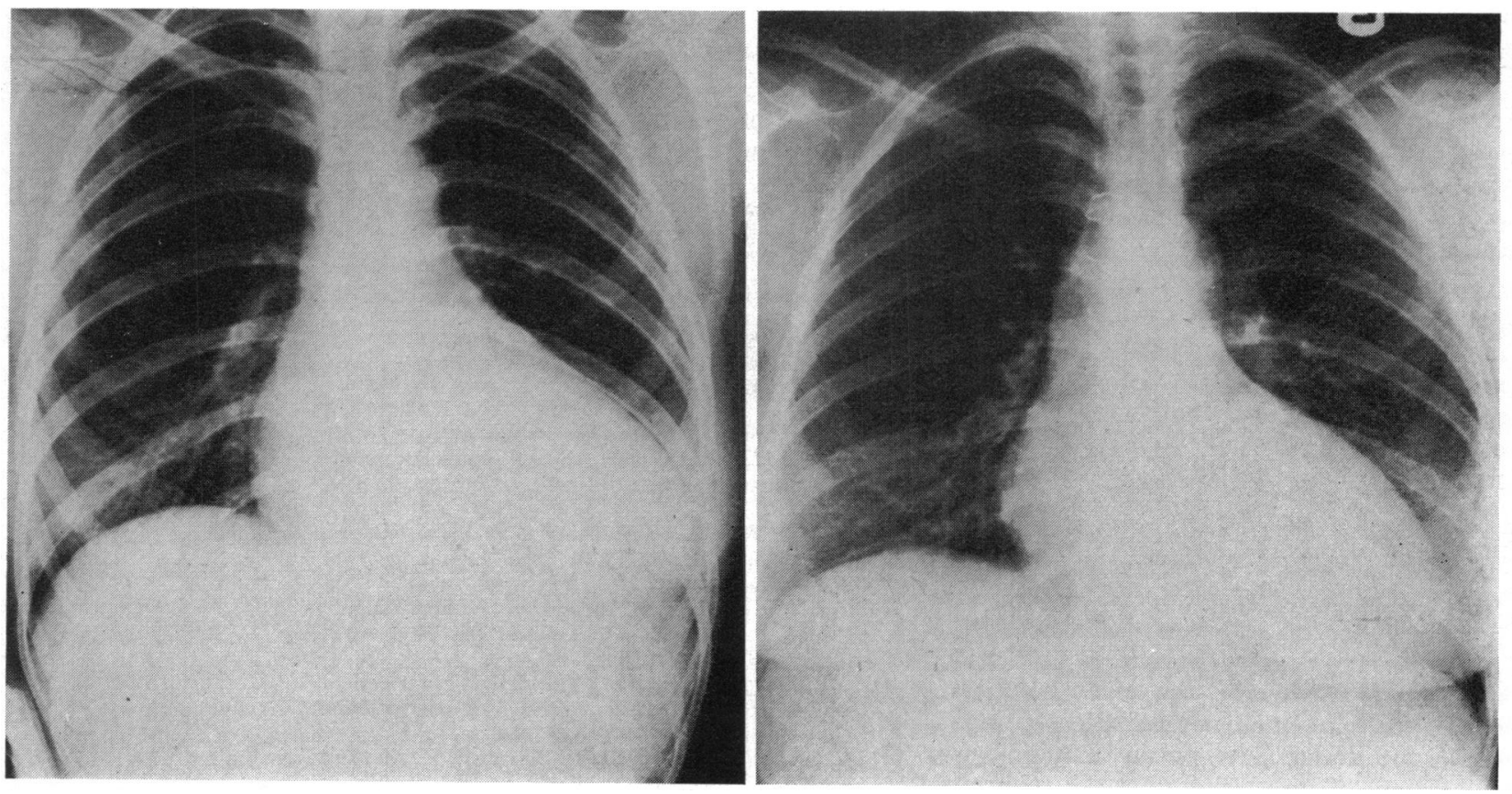
after. However, there is the danger that coumarin-type anticoagulants given to the mother during pregnancy may cross the placenta and harm the foetus, particularly causing cerebral haemorrhage and permanent brain damage (Mahairas and Weingold, 1963).

DiSaia's (1966) patient had a Starr-Edwards mitral valve prosthesis and received warfarin throughout the pregnancy. The infant was born blind and mentally retarded. This patient had a pulmonary infarct during pregnancy but no evidence of systemic thromboembolism. Bennett and Oakley (1968) reported the case of a woman, whose mitral valve had been replaced by a Hammersmith Alvarez type prosthesis, who had several episodes of arterial thromboembolism despite apparently adequate anticoagulation throughout pregnancy. From the 29th week she developed signs of mitral valve obstruction and died 7 days after caesarean section performed at $30 \frac{1}{2}$ weeks. Necropsy revealed a mitral valve prosthesis completely immobilized by thrombus.

The occurrence of thromboembolic complications and therefore the need for longterm anticoagulant therapy remain a serious objection to allowing the continuation of pregnancy with Starr-Edwards or similar prosthetic valves in situ. The freedom from thromboembolic complications in patients with homograft aortic valves makes their management easier in any situation and especially in pregnancy. This present patient had nothing to suggest embolic phenomena and there was never any indication for anticoagulants.

Though aortic diastolic and systolic murmurs were present after her operation, there has been no clinical or radiological evidence that the residual lesion is haemodynamically significant. Barratt-Boyes et al. (1965) recorded an aortic diastolic murmur in 48 patients $(52 \%)$ of a series with aortic valve homografts. In 15 of these patients the aortic regurgitation was haemodynamically significant and 4 patients had successful second operations. A diastolic murmur occurred more commonly in those patients whose original lesion was aortic regurgitation. Hoeksema et al. (1967) recorded an aortic diastolic murmur in 44 per cent of patients whom they were able to trace 12 months after homograft aortic valve replacement. In a more recent review, Brandt et al. (1969) submitted $5 \mathrm{I}$ patients with aortic homograft valves to cine-angiocardiography, using a technique designed to permit a radiological assessment of the degree of aortic regurgita- tion and to reveal details of the anatomy of the homograft valve. In the whole series $7 \mathrm{I}$ per cent had no significant aortic regurgitation. These authors found good agreement between the radiological and clinical assessment of aortic regurgitation, indicating that standard clinical methods can be applied to patients with homograft aortic valve regurgitation.

This patient would come into the first, or trivial, of their clinical criteria, i.e. normal pulse and blood pressure, with an aortic diastolic murmur present. Her electrocardiogram showed a left bundle-branch block pattern from the time of open-heart surgery; this change was presumed to be a result of the operation. Barratt-Boyes et al. (I965) recorded a permanent complete heart block produced at operation in one of their patients.

A possible complication of pregnancy in patients with homograft or prosthetic valves is endocarditis. Lacerations, episiotomies, and instrumentation at the time of delivery are possible sources of infection. These valves are susceptible to both bacterial and fungal organisms, and Conway et al. (1968) described 2 cases of candida endocarditis occurring after homograft replacement. They pointed out the dangers of antibiotic therapy in the causation of this complication. In the management of this patient it was considered better to give antibiotics to cover the delivery and puerperium together with nystatin, in the hope of reducing the risk of candida infection; and to date this patient has shown no signs of endocarditis.

I would like to thank Dr. C. S. McKendrick, under whose care this patient was originally investigated, Mr. P. J. Molloy who undertook the open-heart surgery, and Mr. P. Walker who was responsible for the obstetric care.

\section{References}

Barratt-Boyes, B. G., Lowe, J. B., Cole, D. S., and Kelly, D. T. (1965). Homograft valve replacement for aortic valve disease. Thorax, 20, 495 .

Bennett, G. G., and Oakley, C. M. (I968). Pregnancy in a patient with a mitral-valve prosthesis. Lancet, $1,616$.

Brandt, P. W. T., Roche, A. H. G., Barratt-Boyes, B. G., and Lowe, J. B. (1969). Radiology of homograft aortic valves. Thorax, 24, 129.

Conway, N., Kothari, M. L., Lockey, E., and Yacoub, M. H. (1968). Candida endocarditis after heart surgery. Thorax, 23, 353.

DiSaia, P. (1966). Pregnancy and delivery of a patient with a Starr-Edwards mitral valve prosthesis. Obstetrics and Gynecology, 28, 469.

Hoeksema, T. D., Titus, J. L., Giuliani, E. M., and Kirklin, J. W. (1967). Early results of use of 
homografts for replacement of the aortic valve in man. Circulation, 35 Suppl. I, p. 9.

Mahairas, G. H., and Weingold, A. B. (1963). Fetal hazard with anticoagulant therapy. American fournal of Obstetrics and Gynecology, 85, 234.
Turner, R. W. D., and Kitchin, A. H. (1968). Pregnancy after mitral-valve prosthesis. Lancet, $1,862$.

Ueland, K., Tatum, H. J., and Metcalfe, J. (I966). Pregnancy and prosthetic heart valves. Obstetrics and Gynecology, 27, 257. 